\title{
光电联合催化的研究进展
}

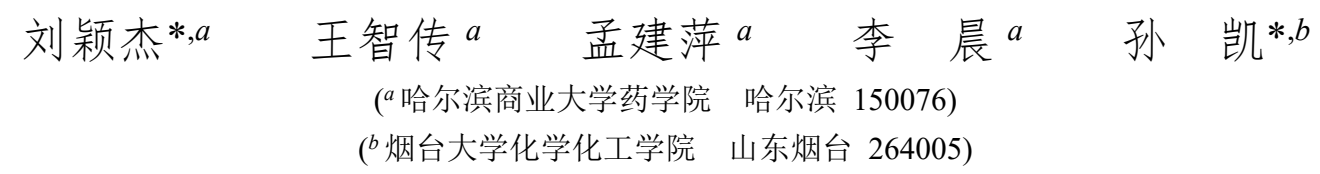

\begin{abstract}
摘要 近年来, 温和、绿色的光化学和电化学反应在有机合成中得到了广泛的应用. 为了进一步提升光、电反应潜力, 有机化学家们致力于在单一反应体系中使用这两种策略来促进有机转化. 一系列光电联合催化策略被开发出来, 目前 主要的光电联合催化策略是电化学介导的光氧化还原催化. 此外, 光激发辅助、电化学主导氧化还原的光电联合催化 策略也逐渐展现出其在有机合成中的潜力. 这些策略实现了光化学与电化学优缺点的互补, 能解决光化学和电化学所 不能解决的部分问题, 如去除使反应复杂化的氧化还原剂, 在温和的条件下生成活性高的中间体等. 按照现有的光电 联合催化反应, 分类总结光电联合催化策略的研究进展, 并探讨了部分反应可能的机理.
\end{abstract}

关键词 光氧化还原催化; 电催化; 光电化学

\section{Research Progress of Photoelectric Co-catalysis}

\author{
Liu, Yingjie Wang, Zhichuan $^{a} \quad$ Meng, Jianping $^{a} \quad$ Li, Chen ${ }^{a} \quad$ Sun, Kai*,b \\ ( ${ }^{a}$ School of Pharmacy, Harbin University of Commerce, Harbin 150076) \\ ( ${ }^{b}$ School of Chemistry and Chemical Engineering, Yantai University, Yantai, Shandong 264005)
}

\begin{abstract}
Photochemical and electrochemical reactions, which are mild and green, have been widely used in organic synthesis in recent years. To push the limits of both synthetic technologies, organic chemists have focused on using these two strategies to promote organic transformation in a single reaction system. A series of photoelectrochemical strategies have been developed, and the main one at present is electrochemically mediated photoredox catalysis. In addition, photoexcitation-assisted electroredox strategies have also gradually shown their potential in organic synthesis. These strategies realize the complementary advantages and disadvantages of photochemistry and electrochemistry, and can solve the problems that can not be solved by a single synthetic technology, such as removing oxidizing reducing agents that complicate the reaction, generating intermediates with high activity under mild conditions, and so on. In this paper, the research progress of photoelectrochemical strategies is summarized according to the existing photoelectric catalysis reactions, and the possible mechanism of some reactions is discussed.
\end{abstract}

Keywords photoredox catalysis; electrocatalysis; photoelectrochemistry

1991 年, 美国化学会(ACS)提出 “绿色化学” 的概 念，旨在利用化学原理和方法从源头上减少或避免污染 物的排放, 以达到环境保护的目的. 世界上很多国家已 经把 “化学的绿色化” 作为新世纪化学进展的主要方向 之一. 因此, 近年来不断有新的有机合成方法涌现出来. 光和电都是廉价、绿色、可持续的清洁能源. 光催化可 以通过光诱导单电子转移反应生成活泼有效的中间体, 如自由基、自由基离子等, 从而构建其他方法难以制备 的分子结构. 电化学合成中可以通过电解实现有机小分
子或媒介与电极和电解液之间的电子转移, 电能与化学 能的相互转化, 导致旧化学键的断裂和新化学键的生 成，更容易发现新的有效合成中间体. 而且光催化和电 化学分别以光和电作为能源使用, 消除了对强化学氧化 剂和还原剂的依赖, 从而使电化学和光催化反应在温和 的条件下进行, 通常也减少了对环境的影响. 因此, 光 催化和电化学在 “绿色化学” 中扮演着重要的角色, 也 更加受到有机化学家的青睐.

\footnotetext{
* Corresponding authors. E-mail: liuyj691@nenu.edu.cn; sunk468@nenu.edu.cn

Received June 26, 2021; revised August 20, 2021; published online September 2, 2021.

Project supported by the Youth Project of Natural Science Foundation of Heilongjiang Province (No. YQ2019B004).

黑龙江省自然科学基金优秀青年(No. YQ2019B004)资助项目.
} 


\section{1 电化学}

19 世纪, Faraday ${ }^{[1]}$ 实现了乙酸电解制烃, Kolbe ${ }^{[2]}$ 实 现了电化学脱羧二聚, Schoenbein ${ }^{[3]}$ 实现了三氯甲基磺 酸的还原脱卤, 从而开创了电化学有机合成领域[4-5]. 电 化学反应通常发生在电极上, 电子充当氧化还原剂, 分 子通过得到或者失去电子, 在阳极发生氧化反应或者在 阴极发生还原反应(Figure 1). 因此电化学合成可以在无 外加氧化剂条件下实现氧化交叉偶联反应, 而且在化学 键形成过程中一般以释放出的无害氢气作为唯一副产 物 ${ }^{[6]}$. 与传统有机合成相比, 电化学更加符合绿色化学 的要求, 能构建出传统化学较难合成的分子, 并对分子 进行选择性的修饰. 此外, 电化学可以通过电极电位控 制反应历程, 提高主反应的选择性. 但电化学合成的过 程中, 电极表面产生的自由基会由于来不及迁移到溶液 中就发生二次氧化、自由基二聚等副反应. 所以, 在电 化学合成的过程中通常加入氧化还原介质进行间接电 解, 使自由基中间体在均相体系中生成, 并与底物充分 反应，从而减少副作用. 但由于生成的自由基中间体氧 化电势比前体低, 极易过度氧化. 此外, 在复杂的反应 体系中, 如果电化学合成的过程中需要高电位才能获得 高活性中间体, 在极端电位下将会使反应不受控制, 降 低产物的化学选择性.

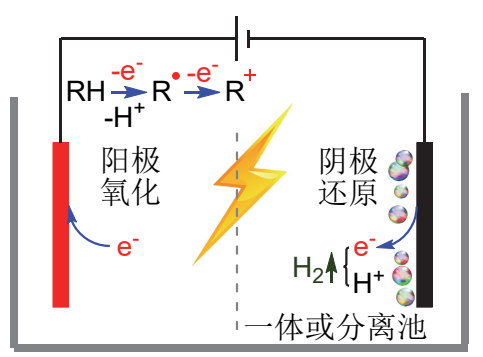

图 1 电化学反应示意图

Figure 1 Schematic diagram of electrochemical reaction

\section{2 光氧化还原催化}

2008 年, Yoon 等 ${ }^{[7]}$ 发现 $\mathrm{Ru}$ (bipy) ${ }_{3} \mathrm{Cl}_{2}$ 是一种非常有 效的烯类 $[2+2]$ 环加成光催化剂. MacMillan 等 ${ }^{[8]}$ 将光氧 化还原催化与有机催化结合起来, 以 $\mathrm{Ru}(\mathrm{bpy})_{3}^{2+}$ 为光催 化剂实现了醛的不对称烷基化. 2009 年, Stephenson 等 ${ }^{[9]}$ 以 $\mathrm{Ru}(\mathrm{bpy})_{3} \mathrm{Cl}_{2}$ 为光催化剂, 开发了无锡还原脱卤催化 方法. 自此利用光氧化还原催化开发新型反应 ${ }^{[10]}$ 受到 了有机合成界的广泛关注. 与传统的氧化还原相比, 光 氧化还原催化体系通常避免使用化学计量氧化剂、还原 剂或合成自由基引发剂, 大多数情况下反应条件更温 和. 由于大多数有机分子不具备吸收可见光所需要的结 构特征, 需要光敏催化剂传导. 而近些年来, 光敏催化
剂的开发和使用也促进了光氧化还原催化研究的发展. 光敏催化剂在光激发下由基态变为激发态, 获得更强的 氧化性和还原性, 并以单电子转移为主要作用方式与有 机底物或试剂反应, 产生高活性的中间体. 其中单电子 转移又分为还原淬灭和氧化淬灭, 其独有的催化循环模 式决定了光催化擅长实现氧化还原中性反应 ${ }^{[1]}$. 除单电 子转移外, 光敏催化剂也可以以能量转移 ${ }^{[12]}$ 的方式与 底物作用(Figure 2). 然而, 要实现净氧化或还原反应需 要使用末端氧化剂或还原剂作为牺牲试剂[13]. 这些牺 牲试剂与催化剂反应后也会产生相应的副产物, 这些副 产物以及氧化剂、还原剂都可能通过与底物、催化剂或 活性中间体反应, 使反应体系复杂化. 此外, 光催化氧 化还原剂还会受其激发态电位的限制, 使其氧化还原范 围受限.

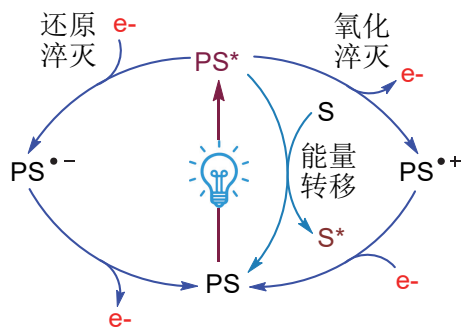

图 2 光催化循环

Figure 2 Photocatalytic cycle

\section{3 光电联合催化}

1979 年, Moutet 和 Reverdy ${ }^{[14]}$ 首先发现了光化学与 电化学的结合. 1982 年, Moutet 和 Reverdy ${ }^{[15]}$ 报道了 $N, N, N^{\prime}, N^{\prime}$-四苯基对苯二胺(TPPD)自由基阳离子的电生 成及其在紫外光的光激发下使苯甲醇氧化成苯甲醛. 直 到近几年, 光电联合催化在有机合成中的应用 ${ }^{[16-18]}$ 才得 到有机合成化学家的重视. 由于光氧化还原催化在实现 净氧化过程中需要加入一定量的化学氧化剂, 使反应变 得复杂, 而电化学易于实现净氧化反应, 却容易过度氧 化. 光催化氧化还原剂的催化范围受激发态电位的限 制, 而电化学虽然可以在不依赖激发态的情况下, 以极 端电位获得高活性中间体，但在极端电位下将会使反应 不受控制, 降低产物的化学选择性. 光氧化还原催化和 电化学优缺点互为补充, 如果将两者结合, 实现电化学 介导光氧化还原催化, 便能解决光氧化还原催化和电化 学所不能解决的部分问题, 如去除使反应复杂化的氧化 还原剂，在温和的条件下生成活性高的中间体，获得极 强的氧化或还原电位以激活惰性键等. 除了电化学介导 的光氧化还原催化外, 光激发辅助、电化学主导氧化还 原的光电联合催化策略也逐渐展现出其在有机合成中 的潜力. 这些光电联合催化策略均属于分子光电催 
化 ${ }^{[19]}$, 利用分子催化剂、采用简单的电极. 另一类光电 联合催化策略属于界面光电催化, 这种策略依赖传统的 光电池, 使用半导体作为光敏阳极. 但光敏阳极本质上 是非均相光敏剂, 通过导线将导带上的电子外引出来, 产生的是光生电流, 部分研究中并没有施加外加电场, 是否属于光电联合催化的范围值得商量. 对于界面光电 催化, 我们在这篇文章将不做讨论. 因此我们将光电联 合催化策略分为以下几类(Figure 3).

(a) 阳极氧化代替化学氧化剂

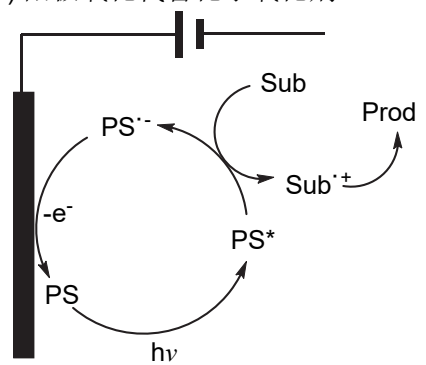

(b) 阳极氧化-光激发产生超级光氧化剂

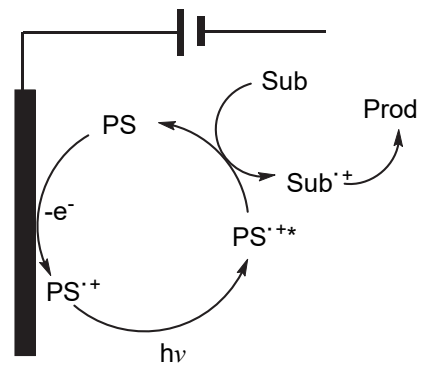

(c) 阴极还原-光激发产生超级光还原剂

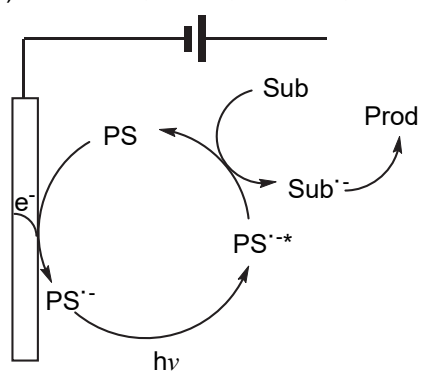

图 3 光电催化

Figure 3 Photoelectrocatalysis

\section{1 阳极氧化代替化学氧化剂实现净氧化光化学反应}

将电化学的 “无痕” 氧化能力与光化学相结合, 以 阳极氧化代替化学氧化剂, 既避免了光催化末端氧化剂 的加入, 也避免了电化学的过度氧化, 从而实现放出氢 气的净氧化光化学反应.

2019 年, Ackermann 等[20]确立了两种催化剂, 即无 金属光催化剂([Mes- $\left.\left.\mathrm{Acr}^{+}\right] \mathrm{ClO}_{4}^{-}\right)$和钌光催化剂([Ru$\left.\left.(\mathrm{bpy})_{3}\right]\left(\mathrm{PF}_{6}\right)_{2}\right)$ ，第一次利用光电联合催化的方法实现了 $\mathrm{C}-\mathrm{H}$ 三氟甲基化(Scheme 1). 利用光电联合催化的方 法, 三氟甲基自由基能有效地生成, 并很容易地参与分
子间的 $\mathrm{C}-\mathrm{H}$ 氧化转化. 相比于光氧化还原催化 ${ }^{[21]}$ 和电

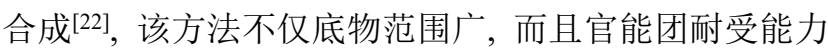
强. Ackermann 等通过改良实验装置使得电氧化和光催 化步骤在时间和空间上分离, 在流动装置中进一步实现 了 $\mathrm{C}-\mathrm{H}$ 三氟甲基化.

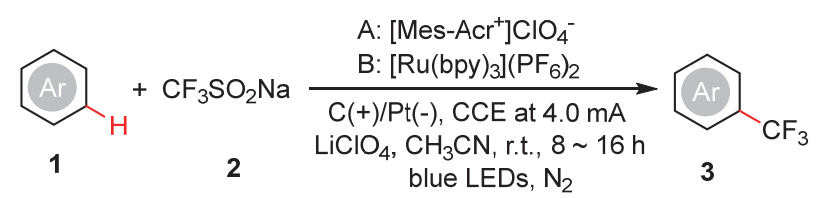

图式 1 光电催化下芳烃 $\mathrm{C}-\mathrm{H}$ 的三氟甲基化反应 Scheme 1 Trifluoromethylation of aromatic hydrocarbon $\mathrm{C}-\mathrm{H}$ under photoelectric catalysis

2019 年, 徐海超课题组 ${ }^{[23]}$ 将光氧化还原催化和电 催化相结合, 在无化学氧化剂的条件下以有机染料 $\left[\mathrm{Mes}-\mathrm{Acr}^{+}\right] \mathrm{ClO}_{4}^{-}$为催化剂, 三氟醋酸(TFA)为酸性添加 剂, 在 $\mathrm{MeCN} / \mathrm{H}_{2} \mathrm{O}(V: V=2: 1)$ 的混合溶剂体系中进 行, 实现了 $\mathrm{C}-\mathrm{H}$ 杂芳烃与有机三氟硼酸盐的烷基化反

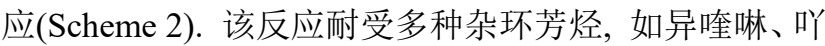
啶、菲啶、酞嗪和嘌呤等, 并且具有良好的区域选择性. $\alpha$-烷氧基和叔烷基自由基的氧化电位远低于有机三氟 硼酸盐, 容易发生过度氧化. 但利用光电联合催化的方 法, 在增加 $\left[\mathrm{Mes}-\mathrm{Acr}^{+}\right] \mathrm{ClO}_{4}^{-}$催化剂的用量或使用 $4 \mathrm{CzIPN}$ 作催化剂的情况下, $\alpha$-烷氧基和叔有机三氟嗍酸 盐均发生了反应，克服了电化学产生的富电子烷基自由 基过度氧化的缺点.

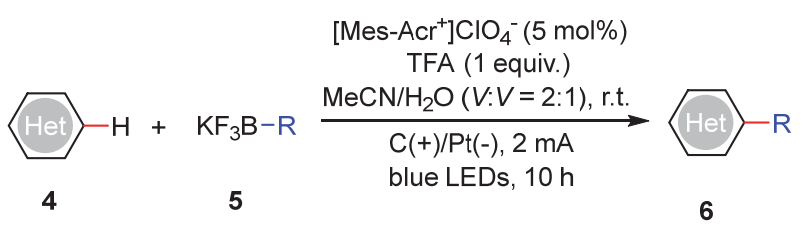

图式 2 光电催化下 $\mathrm{C}-\mathrm{H}$ 杂芳烃与有机三氟嗍酸盐的烷基化 反应

Scheme 2 Alkylation of $\mathrm{C}-\mathrm{H}$ heteroaromatics with organic trifluoroborate under photoelectric catalysis

以 4-甲基喹啉为例，其反应机理如下(Scheme 3): 有机染料 Mes-Acr ${ }^{+}$在光照射下变为激发态 $\mathrm{Mes}^{-} \mathrm{Acr}^{+*}$. Mes-Acr ${ }^{+*}$ 与有机三氟硼酸盐之间发生单电子转移生成 自由基 Mes-Acr和烷基自由基. 一方面，自由基 MesAcr’在阳极表面氧化，生成基态催化剂; 另一方面，烷 基自由基与质子化的 4-甲基喹啉 7 反应生成自由基阳离 子 $\mathbf{8}$, 自由基阳离子 $\mathbf{8}$ 失去一个质子生成自由基中间体 9. 电子从 9 转移至有机染料 Mes-Acr ${ }^{+}$得到最终产物 $\mathbf{1 0}$ 和 Mes-Acr'. 当烷基自由基为异丙基自由基时，质子化 4-甲基 2-异丙基喹啉 10 的还原电位为 $-1.19 \mathrm{~V}$. 基态催 
化剂 Mes-Acr ${ }^{+}$还原电位为 $-0.57 \mathrm{~V}$, 在热力学上有利于 9 转移一个电子给 Mes-Acr ${ }^{+}$生成 10.

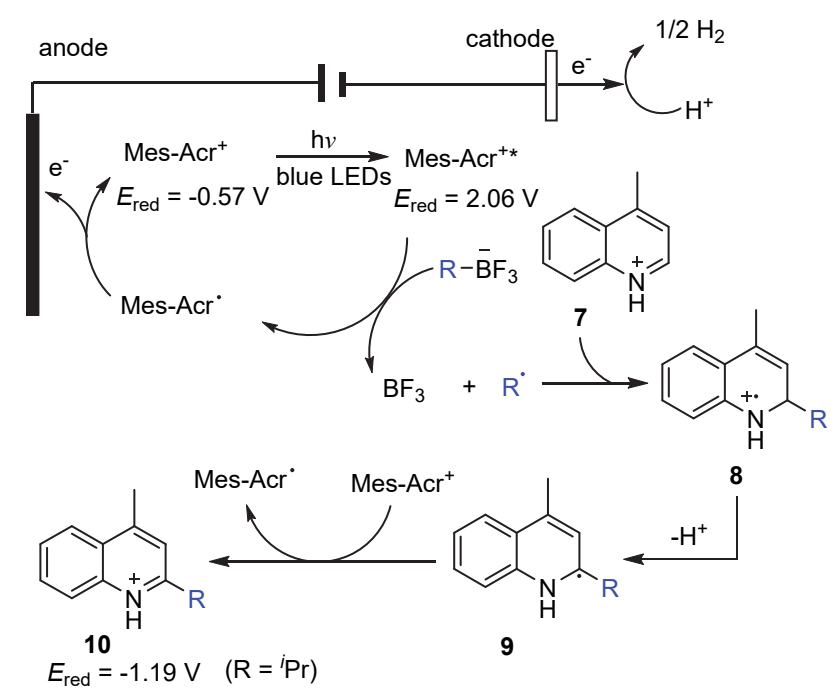

图式 3 4-甲基喹啉光电催化下氮邻位的烷基化反应机理 Scheme 3 Alkylation mechanism of nitrogen ortho-position under photoelectric catalysis of 4-methylquinoline

2020 年, 徐海超课题组 ${ }^{[24]}$ 利用光电联合的方法, 通 过析氢在无化学氧化剂的条件下实现了杂环芳烃与羧 酸和草酸的直接脱羧 $\mathrm{C}-\mathrm{H}$ 烷基化和氨基甲酰化 (Scheme 4). 虽然利用光催化也能实现杂环芳烃的无氧 化脱羧基 $\mathrm{C}-\mathrm{H}$ 烷基化反应 ${ }^{[25-26]}$, 但芳烃和羧酸底物反 应范围有限. 而通过电化学脱羧生成的碳自由基容易产 生不良的二聚反应 ${ }^{[27]}$ 或过度氧化成碳正离子 ${ }^{[28]}$. 利用 光电联合的方法, 不仅克服了光催化和电化学所面临的 问题，而且扩展到十克级反应.

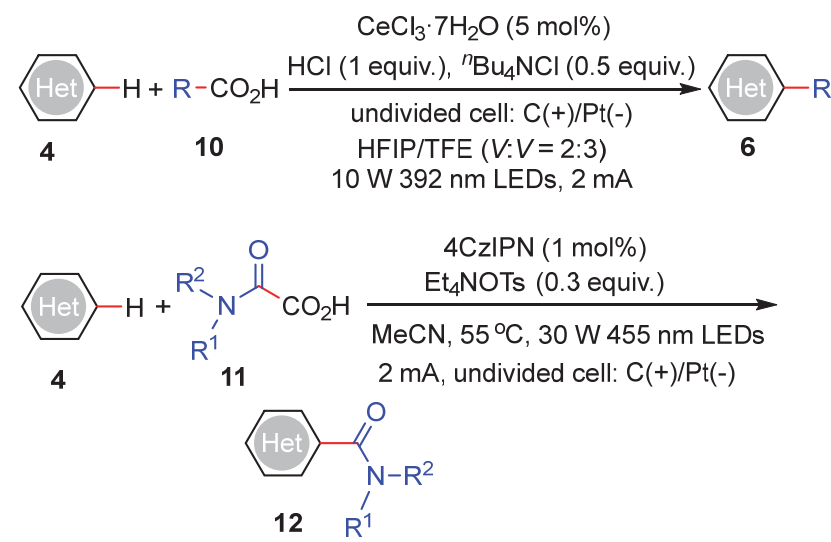

图式 4 杂环芳烃与羧酸和草酸的光电脱羧 $\mathrm{C}-\mathrm{H}$ 烷基化和氨 基甲酰化反应

Scheme 4 Photoelectric decarboxylation of heterocyclic aromatic hydrocarbons with carboxylic and oxalic acids by $\mathrm{C}-\mathrm{H}$ alkylation and carbamylation

2021 年末, 徐海超课题组 ${ }^{[29]}$ 用 4CzIPN 作为分子催
化剂, 通过分子光电催化实现了杂环芳烃与草酸烷基的 $\mathrm{C}-\mathrm{H}$ 烷基化反应(Scheme 5).

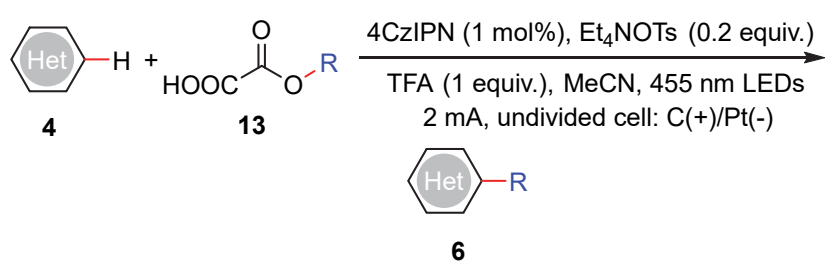

图式 5 杂环芳烃与草酸烷基的 $\mathrm{C}-\mathrm{H}$ 烷基化反应 Scheme $5 \mathrm{C}-\mathrm{H}$ alkylation of heterocyclic aromatic hydrocarbons with alkyl oxalate

2020 年, 雷爱文课题组 ${ }^{[30]}$ 将金属催化、电化学和光 化学结合起来, 开发了一种以亲核叠氮化钠为叠氮化试 剂, 在可见光催化下 $\mathrm{C}\left(\mathrm{sp}^{3}\right)-\mathrm{H}$ 键的电化学氧化叠氮化 方法(Scheme 6). 该方法突破了电化学分子间 $\mathrm{C}\left(\mathrm{sp}^{3}\right)-\mathrm{H}$ 胺化的底物主要集中在 $\mathrm{N} 、 \mathrm{O}$ 原子附近的 $\mathrm{C}\left(\mathrm{sp}^{3}\right)-\mathrm{H}$ 键 ${ }^{[31]}$ 或特殊的苄基 $\mathrm{C}\left(\mathrm{sp}^{3}\right)-\mathrm{H}$ 键上的限制，扩展了其在 生物医学中的应用.

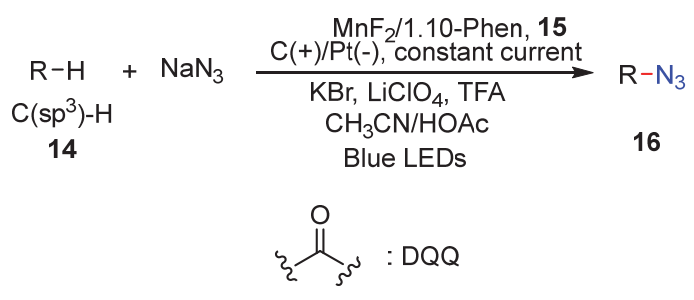

15

图式 6 光电催化下 $\mathrm{C}\left(\mathrm{sp}^{3}\right)-\mathrm{H}$ 键叠氮化反应 Scheme 6 Photoelectrocatalytic azide reaction of $\mathrm{C}\left(\mathrm{sp}^{3}\right)-\mathrm{H}$ bond

其作用机制是(Scheme 7): $\mathrm{NaN}_{3}$ 在阳极表面被氧化 成叠氮化物自由基. 光催化剂 15 在 Blue LEDs 照射下由 基态变为激发态 17 , 激发态 17 诱导 19 上的 $\mathrm{C}\left(\mathrm{sp}^{3}\right)-\mathrm{H}$ 键氢原子转移(HAT)生成 $\mathrm{C}\left(\mathrm{sp}^{3}\right)$ 自由基 20 . 叠氮化物自 由基也可以通过氢原子转移，从 19 上的 $\mathrm{C}\left(\mathrm{sp}^{3}\right)-\mathrm{H}$ 键得 到 $\mathrm{H}$ 原子, 生成 $\mathrm{C}\left(\mathrm{sp}^{3}\right)$ 自由基 $\mathbf{2 0}$. 质子化光催化剂 $\mathbf{1 8}$ 再经阳极氧化失去一个质子生成光催化剂 15 , 从而完 成光催化循环. $\mathrm{N}_{3}^{-}$与 1,10-Phen 或 $\mathrm{OAc}^{-}$等配体配位的 $\mathrm{Mn}(\mathrm{II})$ 形成 $\mathrm{Mn}(\mathrm{II}) / \mathrm{L}-\mathrm{N}_{3}$ 中间体. 经阳极氧化后生成 $\mathrm{Mn}(\mathrm{III}) / \mathrm{L}-\mathrm{N}_{3}$ 中间体, $\mathrm{Mn}(\mathrm{III}) / \mathrm{L}-\mathrm{N}_{3}$ 中间体向 $\mathrm{C}\left(\mathrm{sp}^{3}\right)$ 自由 基 20 转移叠氮化物生成最终产物 21, 同时得到 $\mathrm{Mn}(\mathrm{II}) /$ L 完成 Mn 催化循环.

2020 年, 林松课题组 ${ }^{[32]}$ 开发了一种新的氧化未活 化仲醇的方法(Scheme 8). 即在无化学氧化剂的条件下 将阳极氧化与核黄素光催化结合起来, 以四乙酸核黄素 (RFT)为催化剂, 以硫脲(TU)为共催化剂. 由于黄素催 化范围受到光激发态氧化电位的限制, 黄素催化的醇仅 


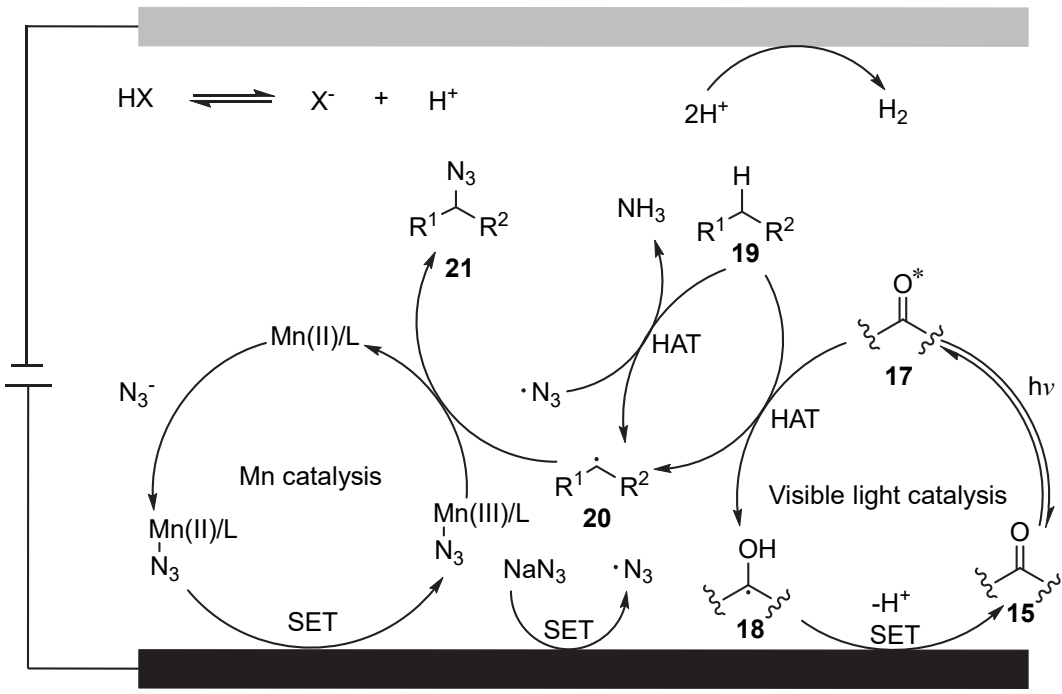

图式 7 光电催化下 $\mathrm{C}\left(\mathrm{sp}^{3}\right)-\mathrm{H}$ 键的叠氮化反应机理

Scheme 7 Azidation mechanism of $\mathrm{C}\left(\mathrm{sp}^{3}\right)-\mathrm{H}$ bond under photoelectric catalysis

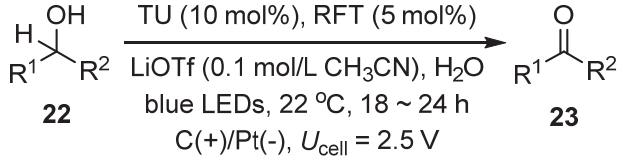

图式 8 RFT 和 $\mathrm{TU}$ 共催化醇的光电反应

Scheme 8 Photoelectric reaction of alcohol co-catalyzed by RFT and TU

适用于电子中性和富电子的茮基醇. 随着催化剂的发 展，阳离子黄素类似物可以氧化缺电子的茮基醇 ${ }^{[33]}$, 但 脂肪族醇还没有成功地参与黄素促进的氧化反应. 林松 课题组利用硫脲和黄素共催化来促进脂肪族醇的氧化, 但光催化中 $\mathrm{O}_{2}$ 的存在导致硫嫝分解为二氧化硫硫嫝. 通过引入电化学, 用阳极氧化代替核黄素光催化中的 $\mathrm{O}_{2}$, 不仅避免了 $\mathrm{O}_{2}$ 对硫腿的降解作用, 而且能高效地产 生自由基中间体和高活性激发态, 将醇的氧化范围从电 子中性和富电子的茮基醇扩大到未活化脂肪族醇.

其反应机理是(Scheme 9): RFT 经光激发转变成激 发态 $\mathrm{RFT}^{*}, \mathrm{RFT}^{*}$ 和硫嫝 25 先进行电子转移, 然后是质 子转移得到硫嫝自由基 26 和半醌型(RFT')-H. 硫脲自由 基 26 得到醇 22 的 $\alpha-\mathrm{H}$ 生成相应的硫脲 25 和醇自由基 24, 醇自由基 24 通过氢原子转移(HAT)进一步与(RFT*)$\mathrm{H}$ 反应, 得到最终的产物 23 和二氢醌形式( RFT)- $\mathrm{H}_{2}$. 最 后，二氢醌形式(RFT)- $\mathrm{H}_{2}$ 在阳极表面被氧化生成基态催 化剂 RFT, $\mathrm{H}^{+}$在阴极还原生成 $\mathrm{H}_{2}$. 在这个反应中的主要 副反应是硫嫝自由基 26 二聚生成二聚体 27 ，二聚体 27 不可逆分解生成 $\mathrm{H}_{2} \mathrm{~S}$ 和尿素 28.

2021 年, Ravelli 等 ${ }^{[34]}$ 用十钨酸四丁基铵(TBADT)作 为光催化剂, 实现了未活化的脂肪族供氢体与苯并噻唑 的脱氢交叉偶联反应(Scheme 10). 反应得到的 2-烷基取

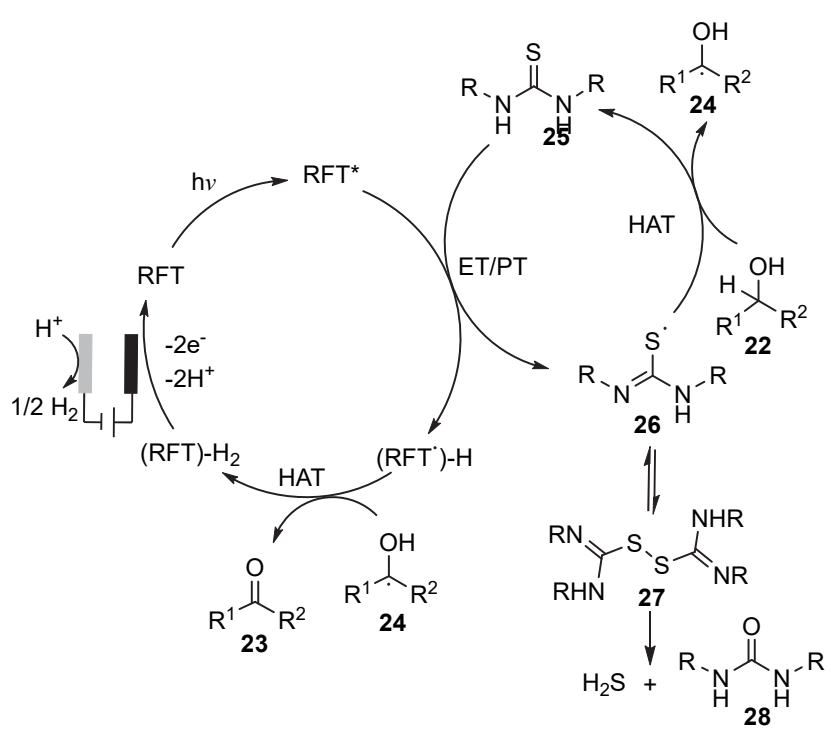

图式 9 RFT 和 TU 共催化醇的光电反应机理

Scheme 9 Photoelectric reaction mechanism of alcohol cocatalyzed by RFT and TU

$$
29
$$

31

图式 10 苯并噻唑与脂肪族供氢体的脱氢交叉偶联反应 Scheme 10 Dehydrogenation cross-coupling of benzothiazole with aliphatic hydrogen donors

代苯并噻唑, 在抗癌、抗菌、抗结核、抗糖尿病和抗抑 郁药物中具有广泛的应用. 
2021 年, 徐海超等 ${ }^{[35}$ 使用有机染料 [Mes-Acr $\left.{ }^{+}\right]-$ $\mathrm{ClO}_{4}^{-}$为光催化剂, 使用 2,2,6,6-四甲基哌啶氧化物 (TEMPO)为共催化剂, 实现了芳烃与唑类化合物的电催 化 $\mathrm{C}-\mathrm{H} / \mathrm{N}-\mathrm{H}$ 交叉偶联反应(Scheme 11). 光的引入避 免了氧化还原剂的使用, TEMPO 作为共催化剂, 可有效 提高反应的产率. 该反应可广泛地用于取代苯, 如联 苯、均三甲苯、烷氧基苯等, 单取代苯都在取代基的对 位进行区域选择性反应.

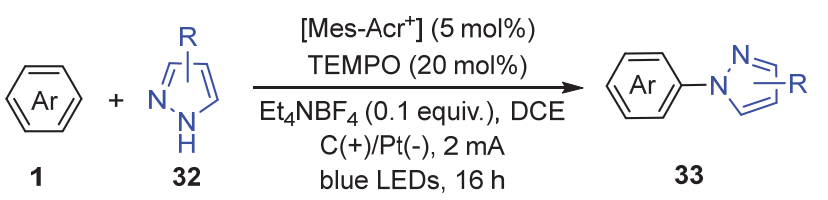

图式 11 电光催化芳烃 $\mathrm{C}-\mathrm{H}$ 唑化反应

Scheme 11 Electrophotocatalytic $\mathrm{C}-\mathrm{H}$ azolation of aromatic hydrocarbons

\section{2 阳极氧化-光激发产生超级光氧化剂}

由于氧化剂在失去电子后氧化能力增加, 激发态氧 化剂的氧化电势也高于基态氧化剂, 所以如果将氧化剂 先经阳极氧化后再经光激发, 获得极强的氧化电位, 产 生超级光氧化剂.

2019 年, Lambert 等 ${ }^{[36]}$ 通过研究发现无色的三氨基 环丙烷阳离子催化剂(TAC), 经电化学氧化后变为三氨 基环丙烷自由基双阳离子 $\left(\mathrm{TAC}^{\cdot 2^{+}}\right)$, 再经光激发得到的 深红色的激发态 $\mathrm{TAC}^{\cdot{ }^{+*}}(3.33 \mathrm{~V}$ vs SCE) 具有很强的氧 化能力, 足以通过单电子转移氧化苯. 使用该催化剂,
Lambert 等实现了惰性芳烃的脱氢 $\mathrm{C}-\mathrm{N}$ 偶联反应 (Scheme 12). 而采用直接电解的方法, 则需要更高的电 极电位, 不仅产率低, 而且反应条件不温和, 不利于控 制反应的历程. 此外, TAC 催化剂是一种稳定的固体, 可由五氯环丙烷和顺-2,6-二甲基哌啶在多克规模的一 锅法中合成, 无需柱纯化, 更有利于光电催化的研究.

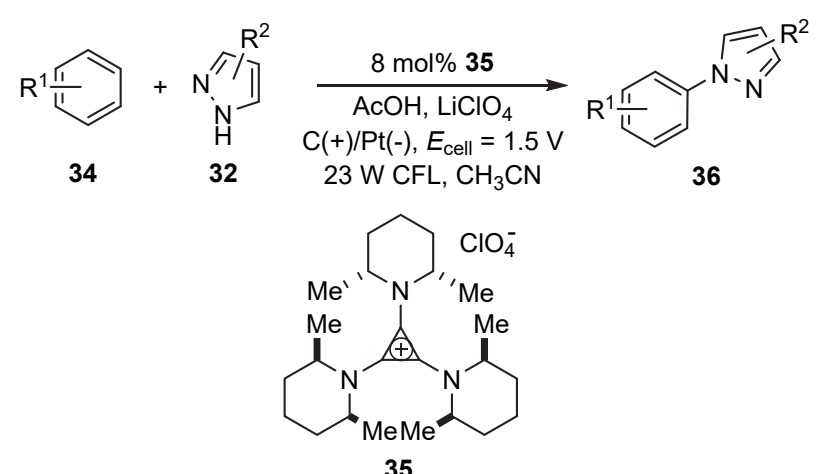

图式 12 芳烃和氮杂芳烃的电光催化偶联

Scheme 12 Electrophotocatalytic coupling of arenes and nitrogen heteroaromatics

以苯和 $1 H$-吡坐 4-羧酸乙酯为例, 其反应机理如下 (Scheme 13): 三氨基环丙烷阳离子 37 在阳极失去电子 后变为三氨基环丙烷自由基双阳离子 $\mathbf{3 8}, \mathbf{3 8}$ 经光激发后 生成激发态三氨基环丙烷自由基双阳离子 39, 39 通过单 电子转移氧化苯 40 为苯自由基阳离子 $\mathbf{4 1}, 1 H$-吡唑-4-羧 酸乙酯 42 亲核捕获苯自由基阳离子 41 , 脱去质子后生 成 1-苯基吡唑 4-羧酸乙酯自由基 43 , 然后自由基 43

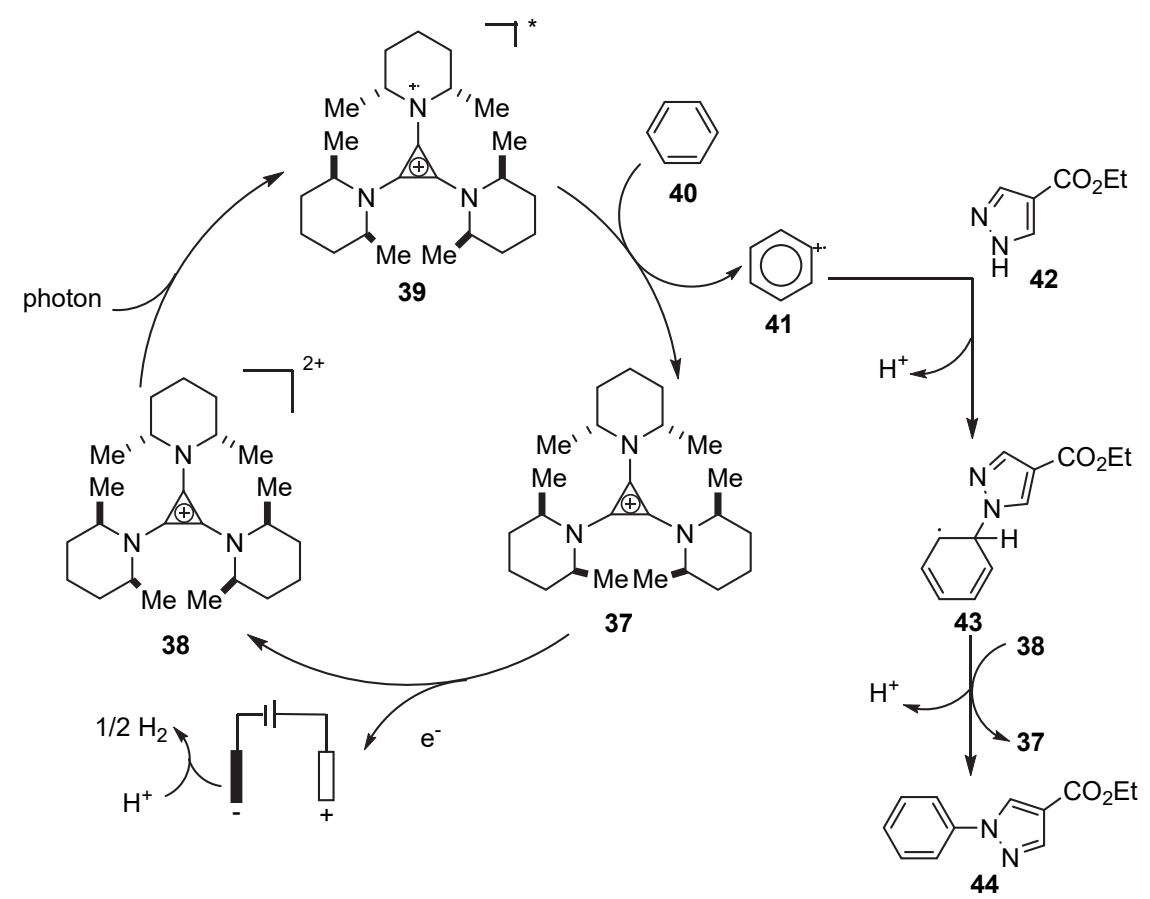

图式 13 光电催化下苯和 $1 H$-吡唑-4-羧酸乙酯的 $\mathrm{C}-\mathrm{H} / \mathrm{N}-\mathrm{H}$ 偶联反应机理

Scheme $13 \mathrm{C}-\mathrm{H} / \mathrm{N}-\mathrm{H}$ coupling reaction mechanism of benzene and $1 H$-pyrazole-4-ethyl carboxylate under photoelectric catalysis 
被 38 氧化, 失去一个质子得到产物 1-苯基吡唑 4-羧酸 乙酯 44.

2020 年, 在 Lambert 等 ${ }^{[37]}$ 以三氨基环丙烷阳离子 (TAC)为催化剂进行光电催化时, 发现 1-氯-4-氟苯和 $1 H$-吡唑-4-羧酸乙酯反应产物是氟化物的取代, 并非是 $\mathrm{C}-\mathrm{H} / \mathrm{N}-\mathrm{H}$ 偶联. 但在电压为 $1.5 \mathrm{~V}, 8 \mathrm{~mol} \% \mathrm{TAC}$ 催化 剂, $\mathrm{LiClO}_{4}$ 、乙酸、乙腈以及白光照射的条件下, 1-氯-4氟苯和 $1 H$-吡唑-4-羧酸乙酯反应的产率仅为 $25 \%$. 为获 得更高的产率，用具有相似的激发态还原电位 $10 \mathrm{~mol} \%$ DDQ (3.18 V vs SCE)代替 TAC 作催化剂, blue LEDs 代 替 CFL, $\mathrm{TBABF}_{4}$ 代替 $\mathrm{LiClO}_{4}$, 反应产率达到 $60 \%$. 从而 在室温以及不使用强碱的条件下, 实现了非活化氟苯的 亲核芳基取代反应(Scheme 14).

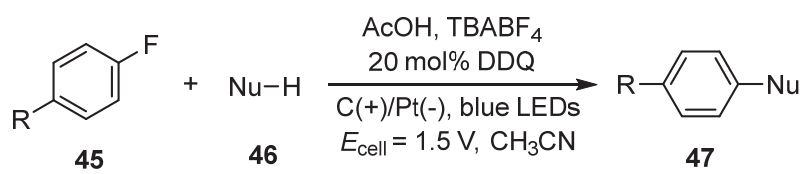

图式 14 未活化芳基氟化物的电光催化芳香族亲核取代反应 Scheme 14 Electrophotocatalytic $\mathrm{S}_{\mathrm{N}} \mathrm{Ar}$ of unactivated aryl fluorides

2020 年, Lambert 等 ${ }^{[38]}$ 理论计算发现, 三氨基环丙 烷阳离子 (TAC) 电氧化后再经光激发得到的激发态 $\mathrm{TAC}^{\cdot 2+*}$ 的氮取代基上具有氨基自由基阳离子特性，可 作为有效的 HAT 受体. 氢自由基转移反应对空间效应 非常敏感, TAC 的受阻特性使化学上相似但空间上有差 异的 $\mathrm{C}-\mathrm{H}$ 键之间发生高度区域选择反应. Lambert 等以 三氨基环丙烷阳离子(TAC)作催化剂, 在电池电压为 1.5 $\mathrm{V}$ 下, TFA 为酸性添加剂, 用紧凑型荧光灯(CFL)在乙腈 和乙酸的作用下实现了醚邻位的 $\mathrm{C}-\mathrm{C}$ 和 $\mathrm{C}-\mathrm{N}$ 偶联反 应(Scheme 15).

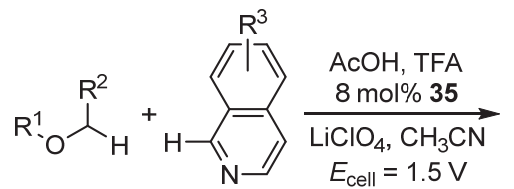

48

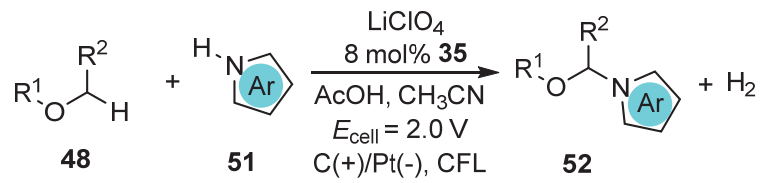

图式 15 光电催化下醚邻位的 C-C 和 C-N 偶联反应 Scheme 15 C-C and C-N coupling reactions of ether ortho sites under photoelectric catalysis

2021 年, Lambert 等 ${ }^{[39]}$ 研究发现乙酰胺基能够促进 烷基化芳烃邻近的 $\mathrm{C}-\mathrm{H}$ 二胺化反应生成 1,2-二胺衍生
物. 这种光电联合催化生成 1,2-二胺衍生物的方法在合 成有价值化合物方面具有巨大的潜力. 而以往的合成策 略通常只在一个 $\mathrm{C}-\mathrm{H}$ 位点发生胺化. 用三氨基环丙烷 阳离子(TAC)作催化剂, 以乙腈为溶剂和氮源, 用 $\mathrm{CFL}$ 照射 $\mathrm{TAC}$ 自由基，产生强氧化的光激发中间体，若以 $\mathrm{Et}_{4} \mathrm{NBF}_{4}$ 为电解质溶液进行光电催化, 将得到 3,4-二氢 咪唑衍生物(Scheme 16). 若以 $\mathrm{LiClO}_{4}$ 为电解质溶液进 行光电催化, 将得到 2-噁唑啉衍生物 (Scheme 17). Lambert 将光电催化二胺化反应进行了一个修改, 用 $\mathrm{KOH}$ 、乙醇和乙二醇处理粗反应混合物并加热回流，能 很好的分离出游离的 1,2-二胺化合物, 在药物合成、催 化配体等方面具有重要的作用.

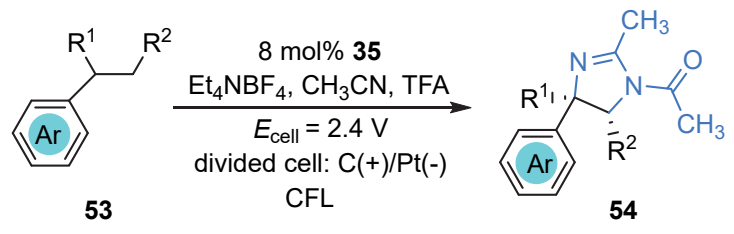

图式 16 光电催化下 3,4-二氢咪唑的合成 Scheme 16 Electrophotocatalytic synthesis of 3,4-dihydroimidazole

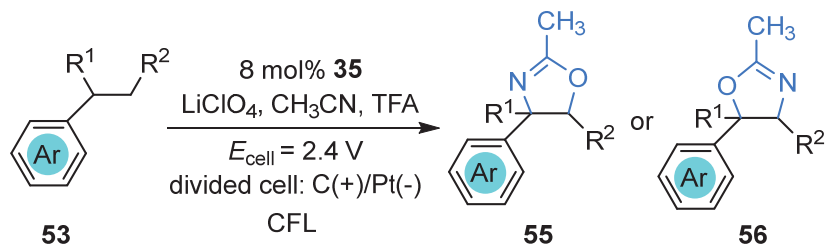

图式 17 光电催化下 2-噁唑啉的合成

Scheme 17 Electrophotocatalytic synthesis of 2-oxazoline

\section{3 阴极还原-光激发产生超级光还原剂}

还原剂在得到电子后还原能力会增加，激发态还原 剂失电子能力也高于基态还原剂，所以如果将还原剂先 经阴极还原后再经光激发，便能获得极强的还原电位， 产生超级光还原剂.

2020 年，继 Lambert 通过研究发现三氨基环丙烷阳 离子催化剂(TAC)后, 与林松课题组 ${ }^{[40]}$ 研究发现 9,10-二 氧葱(DCA)经阴极还原得到相应的自由基阴离子，再经 光激发得到的激发态有高还原电位 $(-3.20 \mathrm{~V}$ vs SCE), 以双戊酰二硼 $\left(\mathrm{B}_{2} \mathrm{pin}_{2}\right)$ 为自由基受体, $5 \mathrm{~mol} \% \mathrm{DCA}$ 为催 化剂, $20 \mathrm{~mol} \%$ 吡啶为添加剂与 $\mathrm{B}_{2} \mathrm{pin}_{2}$ 配位, 并促进形成 以 $\mathrm{B}$ 为中心的持久自由基中间体, $\mathrm{TBAPF}_{6}$ 为电解质，乙 腈为溶剂, 在 blue LEDs 下施加的电池电压为 $3.2 \mathrm{~V}$, 能 将氯苯或溴苯还原成苯自由基(Scheme 18). 芳基卤化 物生成芳基自由基，很大程度上局限于具有相对不稳定 的碳卤键或低还原电位的底物，而通过光电联合催化可 以实现富电子芳基卤化物的还原．该方法能使多种芳基 
卤化物发生嗍化反应, 对许多强还原条件敏感的官能 团, 如酯、酮、酰胺、噻吩和氨基甲酸酯等都具有良好 的耐受性.

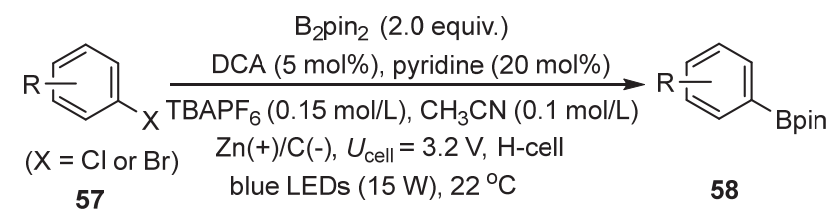

图式 18 芳基卤化物的光电催化嗍化反应

Scheme 18 Photoelectrocatalytic borylation of aryl halides

其反应机理如下(Scheme 19): DCA 催化剂 59 经阴 极还原得到一个电子生成自由基阴离子 60 , 自由基阴 离子 60 再经光激发生成激发态自由基阴离子 61.61 为 芳基卤化物 57 提供一个电子, 生成阴离子自由基中间 体 62 和 DCA 催化剂 59, 阴离子自由基中间体 62 脱去 卤素离子生成芳基自由基 63 , 然后芳基自由基 63 继续 生成官能团化产物 64.

2020 年, Wickens 课题组 ${ }^{[41]}$ 评估了一系列芳基酰亚 胺在可见光照射下的活性和适当的电化学电位, 发现䒺 共轭的 $N$-芳基酰亚胺(NpMI)经阴极还原后再经光激发 可获得超级光还原剂, 能将氯苯直接还原为苯自由基 (Scheme 20). Wickens 以 NpMI 为催化剂评估了许多富 电子的芳基氯底物, 发现含有供电子基的芳基氯底物仍 然经历了有效的 SET 诱导的磷酸化, 并且可以高度选择 性地发生在卤化物位置上. 相对于直解电解, 不仅反应 选择性显著降低, 而且由于自由基的竞争性电化学还 原, 任何速率常数低于 $10^{9} \mathrm{~s}^{-1}$ 的自由基反应都不能发 生.

\section{4 其它光电联合催化反应}

除了上述的光电联合催化反应外，一些光电联合催 化反应中, 电化学主导氧化还原过程, 光照并不引起单 电子转移，而是促进键的断裂生成自由基. 这种光激发 辅助、电化学主导氧化还原的光电联合催化策略鲜有报 道.

2015 年, Zeng 和 Little 等 ${ }^{[42]}$ 在 $n-\mathrm{Bu}_{4} \mathrm{NI}$ 的介导下, 以 Pht- $\mathrm{NH}_{2}$ 为氮源, 实现了烯烃的电催化氮丙啶化(Scheme 21). 根据对照实验、自由基捕获实验以及 Minakata 的 研究 ${ }^{[43]}$, 提出了一种合理反应机理(Scheme 22). 碘化物 在阳极氧化得到 $\mathrm{I}_{2}$, 与 $n-\mathrm{Bu}_{4} \mathrm{NI}$ 形成 $n-\mathrm{Bu}_{4} \mathrm{NI}_{3}, n-\mathrm{Bu}_{4} \mathrm{NI}_{3}$ 在可见光激发下生成 $\mathrm{I}^{*}$ 和 $n-\mathrm{Bu}_{4} \mathrm{NI}_{2}, \mathrm{I}^{*}$ 从 $\mathrm{Pht}-\mathrm{NH}_{2}$ 得到氢 原子形成胺基自由基 70, 胺基自由基 70 被烯烃 68 捕获 形成自由基中间体 71. $n-\mathrm{Bu}_{4} \mathrm{NI}_{2}$ 促进自由基中间体 71 的 氮氢键的均裂，并进行分子内环化得到氮丙啶产物 69.

2018 年, Stahl 课题组 ${ }^{[44]}$ 使用碘作为电化学介质, 在 Hofmann-Lçffler-Freytag(HLF)反应中, 由于高阳极电位 容易导致分子中辅助官能团的分解或氧化, 利用光诱导 中间体 N-I 键的均裂, 使电化学过程在低电极电位下 进行, 反应电位仅需 $0.3 \mathrm{~V}\left(\mathrm{vs} \mathrm{Fc} / \mathrm{Fc}^{+}\right)$, 从而实现电化学 脱氢 $\mathrm{C}\left(\mathrm{sp}^{3}\right)-\mathrm{N}$ 偶联反应(Scheme 23). 作者比较了先前 报道的 HLF 反应的几种机理, 分别通过电子转移一质子 转移一电子转移(ET-PT-ET)生成苠阳离子, 再与氮亲核 试剂反应 ${ }^{[45]}$; 质子耦合电子转移(PCET)生成一个氮中 心自由基促进 1,5-HAT ${ }^{[46]}$ 和溴化物介导的 N-Br 中间体 的形成 ${ }^{[47-48]}$. 但是用碘作为电化学介质比溴化物介导的 所需的电极电位低 $0.4 \mathrm{~V}$, 比电化学 PCET 和 ET-PT-ET

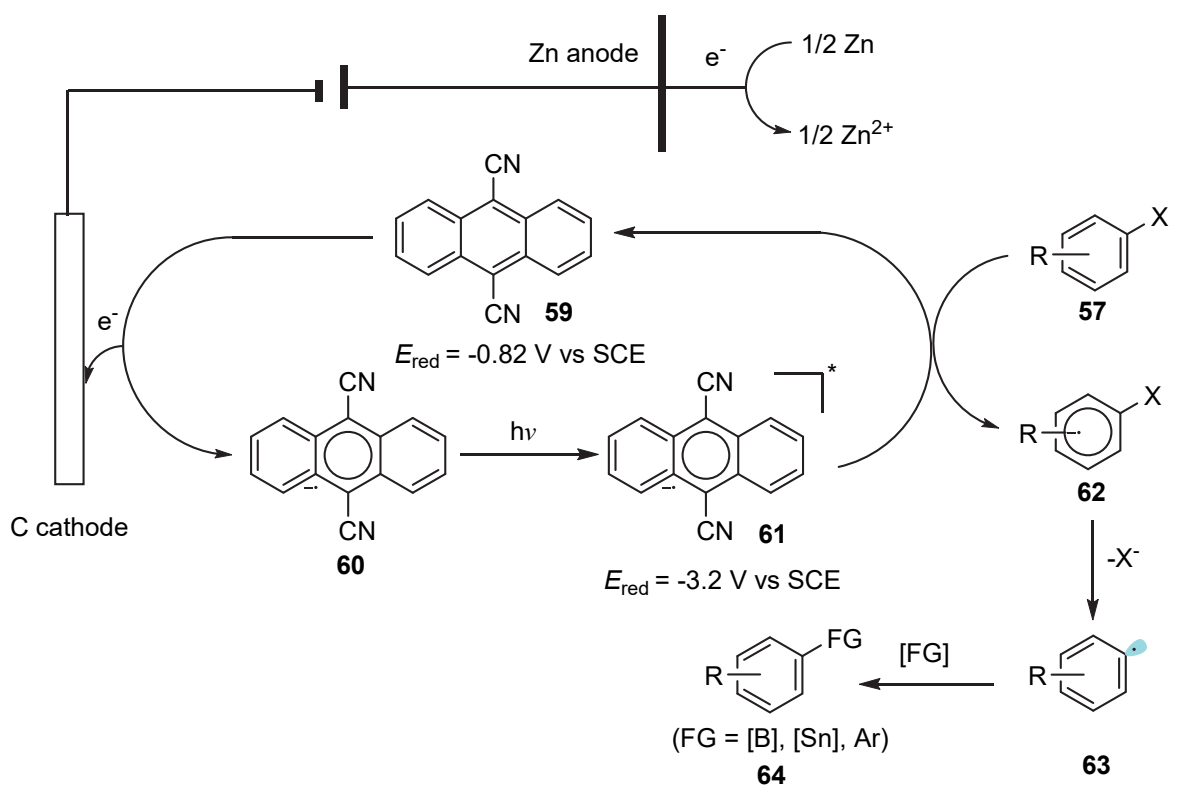

图式 19 芳基卤化物光电催化生成芳基自由基反应机理

Scheme 19 Reaction mechanism of aryl radical generation by photoelectric catalysis of aryl halides 


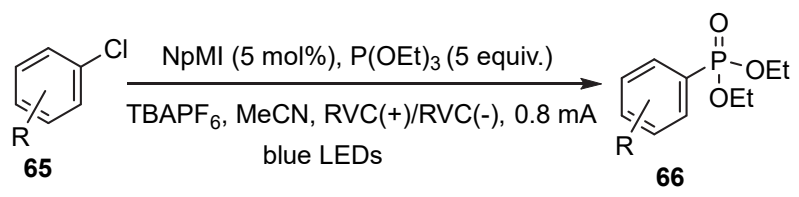

图式 20 芳基氯光电催化磷酸化反应

Scheme 20 Photoelectrocatalytic phosphorylation of aryl chloride

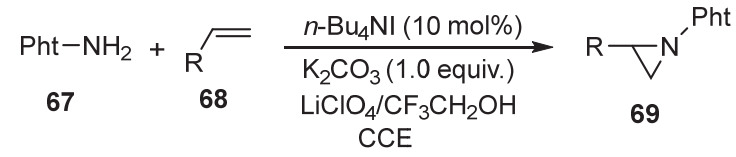

图式 21 烯烃的光电催化氮丙啶化反应

Scheme 21 Photoelectrocatalytic aziridination of olefin

所需的电极电位低 $1 \sim 1.5 \mathrm{~V}$. 与之前光电反应所不同的 是, 在该反应中光照并不引起单电子转移, 而是利用碘 独特的光反应活性 ${ }^{[49]}$, 促进了中间体 $\mathrm{N}-\mathrm{I}$ 键的均裂.

以 $N$-(4-苯基丁基)苯磺酰胺为例, 其反应机理是 (Scheme 24): $N$-(4-苯基丁基)苯磺酰胺(74)在碱的催化下 碘化生成 $N$-碘- $N$-(4-苯基丁基)苯磺酰胺(75), 光解有助 于 $\mathrm{N}-\mathrm{I}$ 键的均裂，生成以 $\mathrm{N}$ 为中心的自由基中间体 76, 然后经过 1,5-HAT 生成烷基自由基 77, 烷基自由基 77 与碘反应产生一种烷基碘化物中间体 78, 它可以通过 附加的氮亲核试剂进行碱促进的亲核置换, 得到目标产 物 79 和 $\mathrm{I}^{-}$. $\mathrm{I}^{-}$在阳极发生氧化生成 $\mathrm{I}_{2}, \mathrm{H}^{+}$在阴极还原生 成 $\mathrm{H}_{2}$.

2020 年, 徐海超课题组 ${ }^{[50]}$ 利用光电联合的方法, 通 过 $\mathrm{H}_{2}$ 演化实现了杂环芳烃和 $\mathrm{C}\left(\mathrm{sp}^{3}\right)-\mathrm{H}$ 供体的 Minisci 反应(Scheme 25). 该方法无需金属催化剂或化学氧化 剂, 并与多种杂环芳烃以及活化和未活化的 $\mathrm{C}\left(\mathrm{sp}^{3}\right)-\mathrm{H}$ 供体表现出广泛的相容性. 此方法以 $\mathrm{Et}_{4} \mathrm{NCl}$ 和 $\mathrm{HCl}$ 分别 作为氯化物源和酸, $\mathrm{Cl}^{-}$在阳极氧化下连续生成低浓度
的 $\mathrm{Cl}_{2}$, 既避免了危险气体 $\mathrm{Cl}_{2}$ 的使用, 又通过 $\mathrm{Cl}_{2}$ 减少 了不必要的烷基氯化物的形成. $\mathrm{Cl}_{2}$ 在光照下发生均裂, 并不引起单电子转移. 由于 $\mathrm{HCl}$ 具有较大的键解离能, 确保氯自由基与多种活化和未活化的脂肪族 $\mathrm{C}-\mathrm{H}$ 键反 应, 将 $\mathrm{C}\left(\mathrm{sp}^{3}\right)-\mathrm{H}$ 转化为碳自由基.

\section{4 结论与展望}

本文对近几年发展的光电联合催化策略进行了分 类总结，这对于利用光电联合催化策略进行有机合成研 究具有重要的意义. 光电联合催化作为新兴的有机合成 策略, 具有光催化和电化学有机合成的优势, 同时也克 服了光催化和电化学在有机合成中的局限性. 对于净氧 化还原反应以及在温和条件下需要在强氧化还原电位 下进行的反应, 光电联合催化具有独特的优势.

尽管光电联合催化策略已经取得了重大进展，但光 电联合催化策略也面临着一些挑战. 目前光电联合催化 策略较为单一, 通常需要光催化剂作为电化学介质. 现 有的光催化剂种类不多、价格昂贵，由于电极直接对光 催化剂转移电子, 导致昂贵的光催化剂消耗严重, 成本 增加. 此外, 在光电联合催化中, 无论是光化学还是电 化学, 均引起电子转移, 难免会相互干扰, 使反应复杂 化. 通过开发不使用光催化剂、光激发辅助、电化学主 导氧化还原的新型光电联合策略，可以有效解决上述问 题. 在光电联合催化过程中, 光吸收、激发态失活、与 底物的反应活性以及光电不同的反应速率等都会引起 光电联合催化的效率问题. 循环伏安法可作为获取光电 联合催化过程中动力学信息的有效工具, 为光电联合催 化提供合理的框架. 目前的光电联合催化实验装置多为 分批式，限制了其在底物范围的研究，通过流动式的光 电联合催化实验装置, 可实现光化学和电化学时间和空

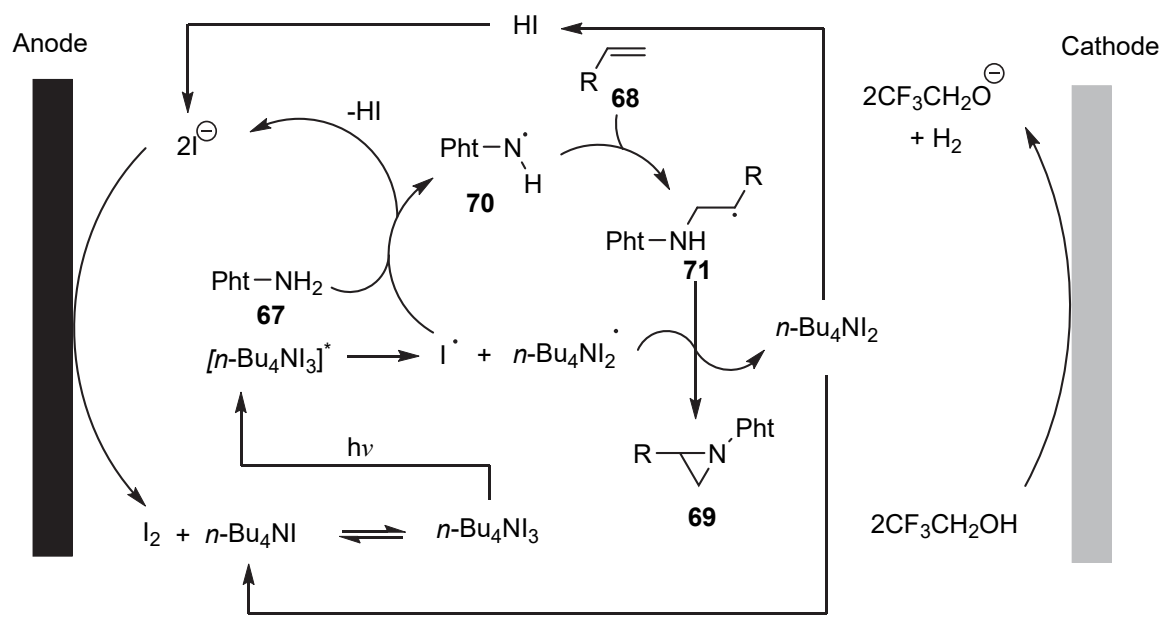

图式 22 烯烃的光电催化氮丙啶化反应机理

Scheme 22 Mechanism of photoelectrocatalytic aziridination of olefin 


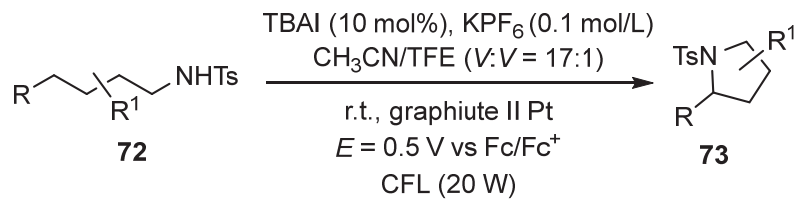

图式 23 碘化物介导的 $\mathrm{C}-\mathrm{H}$ 胺化反应 Scheme $23 \quad \mathrm{C}-\mathrm{H}$ amination mediated by iodide

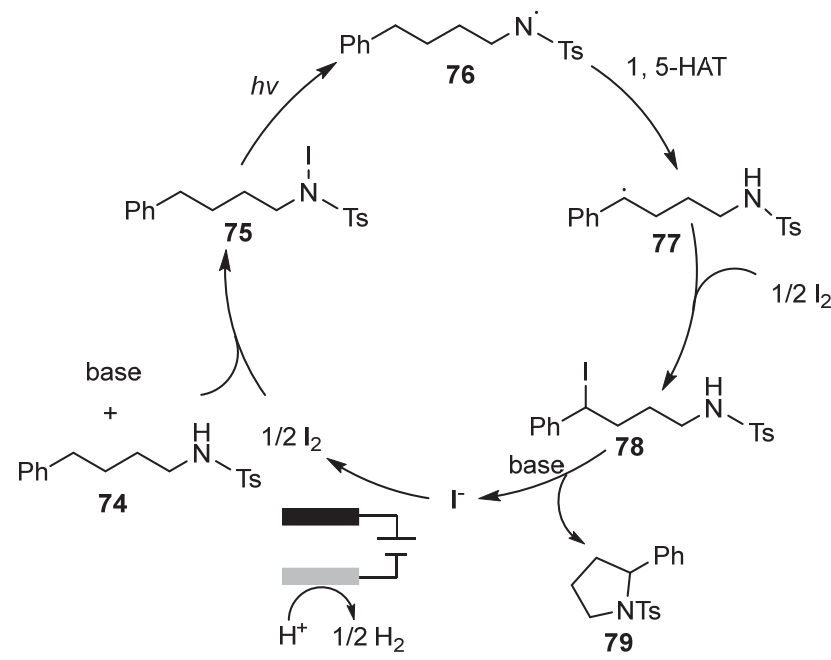

图式 24 碘化物介导的 $\mathrm{C}-\mathrm{H}$ 胺化反应机理

Scheme 24 Reaction mechanism of iodide-mediated $\mathrm{C}-\mathrm{H}$ amination

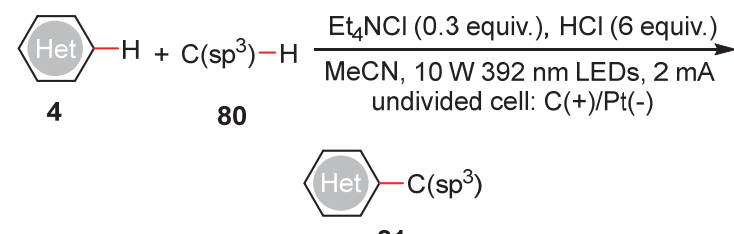

81

图式 25 杂芳烃和 $\mathrm{C}\left(\mathrm{sp}^{3}\right)-\mathrm{H}$ 供体的脱氢交叉偶联反应 Scheme 25 Dehydrogenation cross-coupling of heteroaromatics with $\mathrm{C}\left(\mathrm{sp}^{3}\right)-\mathrm{H}$ donors

间上的有效分离，提高工作效率.

\section{References}

[1] Faraday, M. Ann. Phys. (Leipzig) 1834, 47, 438.

[2] Kolbe, H. J. Prakt. Chem. 1847, 41, 137.

[3] Schoenbein, Ch. F. Liebigs Ann. Chem. 1845, 54, 164.

[4] Liu, Y.-J.; Han, Y.-H.; Lin, L.-Q.; Xu, Y. Chin. J. Org. Chem. 2021, 41, 934 (in Chinese). (刘颖杰, 韩莹徽, 林立青, 许颖, 有机化学, 2021, 41, 934.)

[5] Sun, K.; Lei, J.; Liu, Y.-J.; Liu, B.; Chen, N. Adv. Synth. Catal. 2020, 362, 3709.

[6] Yuan, Y.; Lei, A.-W. Acc. Chem. Res. 2019, 52, 3309.

[7] Ischay, M. A.; Anzovino, M. E.; Du, J.; Yoon, T. P. J. Am. Chem. Soc. 2008, 130, 12886.

[8] Nicewicz, D. A.; MacMillan, D. W. C. Science 2008, 322, 77.

[9] Narayanam, M. R.; Tucker, J. W.; Stephenson, C. R. J. J. Am. Chem. Soc. 2009, 131, 8756.
[10] Gan, Z.-Y.; Li, G.-Q.; Yang, X.-B.; Yan, Q.-L.; Xu, G.-Y.; Li, G.-Y.; Jiang, Y.-Y.; Yang, D.-S. Sci. China: Chem. 2020, 63, 1652.

[11] Xie, J.; Jin, H.; Hashmi, A. S. K. Chem. Soc. Rev. 2017, 46, 5193.

[12] Becker, M. R.; Richardson, A. D.; Schindler, C. S. Nat. Commun. 2019, 10, 5095.

[13] Kong, Y.-L.; Xu, W.-X.; Ye, F.-X.; Weng, J.-Q. Chin. J. Org. Chem. 2019, 39, 3065 (in Chinese).

(孔瑶蕾, 徐雯秀, 叶飞霞, 翁建全, 有机化学, 2019, 39, 3065.)

[14] Moutet, J. C.; Reverdy, G. Tetrahedron Lett. 1979, 20, 2389.

[15] Moutet, J. C.; Reverdy, G. J. Chem. Soc., Chem. Commun. 1982, 654.

[16] Yu, Y.; Guo, P.; Zhong, J.-S.; Yuan, Y.; Ye, K.-Y. Org. Chem. Front. 2020, 7,131

[17] Capaldo, L.; Quadri, L. L.; Ravelli, D. Angew. Chem., Int. Ed. 2019, 58, 17508.

[18] Barham, J. P.; König, B. Angew. Chem., Int. Ed. 2020, 59, 11732.

[19] Chen, N.; Xu, H.-C. Chem. Rec. 2021, 21, 1.

[20] Qiu, Y.; Scheremetjew, A.; Finger, L. H.; Ackermann, L. Chem.Eur. J. 2020, 26, 3241.

[21] Ouyang, Y.; Xu, X.-H.; Qing, F.-L. Angew. Chem., Int. Ed. 2018, 57, 6926.

[22] Deng, Y.; Lu, F.-L.; You, S.-Q.; Xia, T.-R.; Zheng, Y.-F.; Lu, C.-F.; Yang, G.-C.; Chen, Z.-X.; Gao, M.; Lei, A.-W. Chin. J. Chem. 2019, 37, 817.

[23] Yan, H.; Hou, Z.-W.; Xu, H.-C. Angew. Chem., Int. Ed. 2019, 58, 4592.

[24] Lai, X.-L.; Shu, X.-M.; Song, J.; Xu, H.-C. Angew. Chem., Int. Ed. 2020, $59,10626$.

[25] Koeller, J.; Gandeepan, P.; Ackermann, L. Synthesis 2019, 51, 1284.

[26] Tian, W.-F.; Hu, C.-H.; He, K.-H.; He, X.-Y.; Li, Y. Org. Lett. 2019, 21, 6930 .

[27] Kurihara, H.; Fuchigami, T.; Tajima, T. J. Org. Chem. 2008, 73, 6888.

[28] Xiang, J.; Shang, M.; Kawamata, Y.; Lundberg, H.; Reisberg, S. H.; Chen, M.; Mykhailiuk, P.; Beutner, G.; Collins, M. R.; Davies, A.; Del Bel, M.; Gallego, G. M.; Spangler, J. E.; Starr, J.; Yang, S.; Blackmond, D. G.; Baran, P. S. Nature 2019, 573, 398.

[29] Xu, F.; Lai, X.-L.; Xu, H.-C. Synlett 2021, 32, 369.

[30] Niu, L.; Jiang, C.-Y.; Liang, Y.-W.; Liu, D.-D.; Bu, F.-X.; Shi, R.-Y.; Chen, H.; Chowdhury, A. D.; Lei, A.-W. J. Am. Chem. Soc. 2020, 41, 17693.

[31] Yang, Y. Z.; Song, R. J.; Li, J. H. Org. Lett. 2019, 21, 3228.

[32] Zhang, W.; Carpenter, K. L.; Lin, S. Angew. Chem., Int. Ed. 2020, $59,409$.

[33] Zelenka, J.; Svobodová, E.; Tarábek, J.; Hoskovcová, I.; Boguschová, V.; Bailly, S.; Sikorski, M.; Roithová, J.; Cibulka, R. Org. Lett. 2019, 21, 114.

[34] Capaldo, L.; Quadri, L. L.; Merli, D.; Ravelli, D. Chem. Commun. 2021, 57, 4424.

[35] Hou, Z.-W.; Xu, H.-C. ChemElectroChem 2021, 8, 1571.

[36] Huang, H.; Strater, Z. M.; Rauch, M.; Shee, J.; Sisto, T. J.; Nuckolls, C.; Lambert, T. H. Angew. Chem., Int. Ed. 2019, 58, 13318.

[37] Huang, H.; Lambert, T. H. Angew. Chem., Int. Ed. 2020, 59, 658.

[38] Huang, H.; Strater, Z. M.; Lambert, T. H. J. Am. Chem. Soc. 2020, 142, 1698.

[39] Tao, S.; Lambert, T. H. Science 2021, 371, 620. 
[40] Kim, H.; Kim, H.; Lambert, T. H.; Lin, S. J. Am. Chem. Soc. 2020, 142, 2087.

[41] Cowper, N. G. W.; Chernowsky, C. P.; Williams, O. P.; Wickens, Z. K. J. Am. Chem. Soc. 2020, 142, 2093.

[42] Chen, J.; Yan, W.-Q.; Lam, C. M.; Zeng, C. C.; Hu, L.-M.; Little, R. D. Org. Lett. 2015, 17, 986.

[43] Kiyokawa, K.; Kosaka, T.; Minakata, S. Org. Lett. 2013, 15, 4858.

[44] Wang, F.; Stahl, S. S. Angew. Chem., Int. Ed. 2019, 58, 6385.

[45] Herold, S.; Bafaluy, D.; Muñiz, K. Green Chem. 2018, 20, 3191.

[46] Hu, X.; Zhang, G.-T.; Bu, F.-X.; Nie, L.; Lei, A.-W. ACS Catal.
2018, 8, 9370 .

[47] Shono, T.; Matsumura, Y.; Katoh, S.; Takeuchi, K.; Sasaki, K.; Kamada, T.; Shimizu, R. J. Am. Chem. Soc. 1990, 112, 2368.

[48] Zhang, S.; Li, L.; Xue, M.; Zhang, R.; Xu, K.; Zeng, C. Org. Lett. 2018, 20, 3443.

[49] Liu, Y.; Lin, L.-Q.; Han, Y.-H.; Liu, Y.-J. Chin. J. Org. Chem. 2020, 40, 4216 (in Chinese).

(刘洋, 林立青, 韩芗徽, 刘颖杰, 有机化学, 2020, 40, 4216.)

[50] Xu, P.; Chen, P.-Y.; Xu, H.-C. Angew. Chem., Int. Ed. 2020, 59, 14275 .

(Cheng, F.) 